\title{
Introduction: Advancing linguistic politeness theory by using Chinese data
}

\author{
Dániel Z. Kádár \\ Dalian University of Foreign Languages; \\ Research Institute for Linguistics, \\ Hungarian Academy of Sciences \\ dannier@dlufl.edu.cn
}

\begin{abstract}
The present introduction provides an overview of the field of linguistic politeness research. Since Acta Linguistica Academica has diverse scope of inquiries, and linguistic pragmatics has been only one (and perhaps not the most central) of the various areas featured in the journal, it is relevant to provide such an up-to-date overview. My goal is not only to point out how the contributions advance politeness theory, but also to make the research featured in the special issue relevant to academics working in other areas of linguistics.
\end{abstract}

Keywords: linguistic politeness; (im)politeness; pragmatics; Chinese

\section{Introduction}

Linguistic politeness covers all forms of linguistic behaviour through which relationships are formed and maintained; its research is one of the most prominent areas in linguistic pragmatics (section 2). Research on linguistic politeness encompasses explorations of both politeness and impoliteness, and as such it is often referred to as '(im)politeness research'. In the present introductory paper, I refrain from using this technical term and use the generic terms 'politeness' and 'politeness research'.

The present special issue aims to contribute to linguistic politeness research (and pragmatics), by investigating various issues that have been relevant in the field recently. For instance, the contributions explore themes like the 'emancipatory' use of culturally-embedded social and moral ideologies as abstract analytic constructs, the question of how and why one should disentangle the relationship between seemingly 'identical' types of politeness behaviour in monologues, whether the study of first person pronominal forms bear any relevance to politeness research, and so on. The inquiries presented here are interconnected by their theoretical back- 
ground: all of the contributions attempt to theorise linguistic politeness beyond the paradigm of Brown and Levinson (1987) - which until the 2000s largely dominated the field - by using principles of what is often defined as the 'third-wave' of linguistic politeness research (see section 2). Furthermore, all contributors use Chinese language data to investigate politeness theory, hence filling an important gap in the field, considering that in sociopragmatics insufficient work has been done to theorise politeness by using data drawn from languages outside of the mainstream Anglo focus. On many occasions, 'exotic' languages have been preferred as 'testing grounds' for predominantly Western theories (see more details in section 3; also Kádár \& Mills 2011).

To properly frame the contribution the present volume delivers to the field, a longer-than-average introduction is due, considering that Acta Linguistica Academica has diverse scope of inquiries, and linguistic pragmatics has been only one (and perhaps not the most central) of the various areas featured in the journal. ${ }^{1}$ Thus, it is fundamental to overview a number of issues - such as why 'politeness' is fundamental from a sociopragmatic theoretical viewpoint - before moving on to a discussion of the scope of the volume. The relative disciplinary/thematic novelty of this special issue within the journal provides an excellent opportunity to publish a research project of the present scope. To a certain degree, the academic game of linguistic politeness research has been played in a closed field: the 'mainstream' study of politeness has been mainly confined to specialist publication outlets, such as the Journal of Politeness Research. The recent developments in the field have triggered a need for more interdisciplinary interaction between politeness researchers and linguists engaged in other areas. In recent years, linguistic politeness research has become one of the most influential areas of research in linguistic pragmatics, as far as the number of publications and citations are concerned (Culpeper et al. 2017). Because of this, it is now problematic even to rigorously distinguish linguistic politeness and 'socio-pragmatics' in Leech's $(1983,10)$

${ }^{1}$ I would like to express my gratitude to the Editors-in-Chief of Acta Linguistica Academica, Professor Ferenc Kiefer and Professor Katalin É. Kiss for both accepting the present special issue and for providing me with invaluable editorial advice. I am also indebted to the anonymous referees for their invaluable feedback on the proposal of the special issue. It is perhaps needless to say that all remaining problems in the volume are my responsibility. On the institutional level, I would like to acknowledge the support of the Hungarian Academy of Sciences: my time involvement in the present project has been sponsored by the MTA Momentum (Lendület) Research Grant (LP2017-5). 
original sense. ${ }^{2}$ Due to the speed of disciplinary development, an increasing number of researchers have voiced the need to expand linguistic politeness research beyond the boundaries of linguistic pragmatics (Culpeper et al. 2017). Yet, while significant attempts have been made to interconnect politeness research with areas such as cognitive studies and social psychology (Escandell-Vidal 1996; Holtgraves 2005; Bull \& Fetzer 2010), little attention has been devoted to cross-fertilising theoretical politeness research (beyond the conventional Brown and Levinsonian paradigm) with research in other areas of linguistics. A limited number of linguists have applied politeness theory to socially-focused areas in the field, such as sociolinguistics (e.g., Holmes \& Stubbe 2015), dialectology and language contact (e.g., García \& Ortheguy 1983), and historical pragmalinguistics (e.g., Hock 1991). Others have ventured into themes such as the pragmamorphology of expressions that index polite meanings (e.g., Kim 2011) and the relationship between politeness and syntax (Pizziconi 2011). Yet, such cross-linguistic research has not gained momentum as yet. ${ }^{3}$ Thus, this special issue hopes to trigger interdisciplinary interaction between politeness research/sociopragmatics and other areas of linguistic research by presenting contributions that explore issues with broader theoretical significance. I believe that the issues covered are relevant not only to politeness researchers, but also to experts of other areas which focus on language as a socially-situated phenomenon, as well as semantics, research on reflective language (metalinguistics), and other areas in which issues related to the use of language are relevant.

As a disciplinary criterion, politeness and sociopragmatics have been heavily data driven: since the 2000s, it has been largely agreed in the field that politeness can be most reliably captured by using real-life rather than elicited data (Eelen 2001) - although 'real-life' tends to be broadly interpreted in the field (e.g., it may include literary texts). In addition, while corpus-based research of speech acts continues to have validity to the field (Kádár \& House 2019), the mainstream of the field pursues interest

${ }^{2}$ In the present paper, I use 'politeness research' instead of sociopragmatics most of the time. Note that due to this blurred boundary between politeness research and sociopragmatics, Haugh et al. (2013) suggested using alternative labels such as 'interpersonal pragmatics' to distinguish politeness research from a broader set of pragmatic inquiries.

${ }^{3}$ Importantly, this is not to claim that experts of formal linguistics have ignored politeness, but rather that in 'mainstream' politeness research - i.e., in inquiries where scholars examine linguistic politeness for its own sake - other areas of linguistics have been marginal. 
in larger chunks of interactional data. The papers in this volume follow this disciplinary direction, by engaging in data-driven research; the volume covers diverse datatypes, such as face-to-face conversations, literary texts, political texts, and so on and so forth. As a result, the theoretical focus of the volume is on a par with a strong empirical interest in politeness across data types, and as such it is represents a very typical politeness endavour.

The present introduction paper consists of the following parts. Section 2 provides a brief overview of the history of linguistic politeness research (section 2.1), and also it discusses a number of areas where the present special issue delivers a contribution to ongoing research (section 2.2). Since it is beyond the scope of a single introductory paper to overview the politeness area with a comprehensive scope, I devote special attention to terms and concepts that either recur in various contributions of the special issue or are relevant for contextualising the contributions. The section also overviews the scope of the theoretical contribution that the present special issue offers to the field. Finally, section 3 very briefly overviews the contents of the volume.

\section{Linguistic politeness research}

\subsection{The development of the field}

Since linguistic politeness has had many definitions, often with significantly different scope (see an overview in Kádár \& Haugh 2013), let us provide here a broad working definition for both politeness and impoliteness. Linguistic politeness is a pragmatic phenomenon by which language users either express that they care about the feelings of the other, and/or by means of which they indicate that they are aware of their and others' rights and obligations in a particular context. As such, politeness is not limited to etiquette, and pronominal forms such as the second person $\mathrm{T} / \mathrm{V}$ distinction by means of which one can indicate deference and solidarity in many Western languages (see an overview in Braun 1988), but rather it may manifest itself in a wide variety of behavioural phenomena, spanning humour, through forms of endearment, to ritualistic/ceremonial forms of etiquette. For instance, friendly swearing as a form of compassion may serve as an expression of care in certain contexts (see, e.g., Dynel 2012), and as such it may be polite in the technical sense of the word. The diversity of politeness as an analytic construct has motivated inquiries in the field to systematically interconnect seemingly unrelated forms of be- 
haviour by means of which language users work out and maintain their interpersonal relationships.

Linguistic impoliteness covers forms of language behaviour by means of which interactants cause offence to others, i.e., instances of language use that indicate to the other that their feelings are disregarded or violated (Culpeper 2011), and/or their interactional rights are trespassed. Politeness and impoliteness are essentially inseparable, in the respect that they represent two ends of a behavioural-evaluative continuum. Politeness and impoliteness come into existence in the form of evaluative moments in an interaction (Eelen 2001). For instance, there are interactional situations when an interactant intends to be polite but what (s)he utters is evaluated as impolite by her or his speech partner. From an (im)politeness theoretical point of view, such cases are problematic to be categorised as 'polite': as politeness and impoliteness come into existence in interaction, the producer's intention is of secondary importance in the realisation of this phenomenon to its interactional evaluation(s).

The pragmatic research of politeness started in the late 1970s and it has gained momentum with the seminal work of Brown and Levinson (1987). Brown and Levinson argue that it is possible (and necessary) to model politeness as a universal phenomenon, which can be systematically described with the aid of variables in any language. Perhaps the most essential concept in Brown and Levinson's model is 'face', i.e., a person's public self-image: 'negative face' refers to the wish of being unimpeded by the other interactant, whereas 'positive face' refers to the desire of being appreciated. In the Brown and Levinsonian theory, language users form utterances as per the perceived face wishes of their speech partners, and the speech partner may perceive that the speaker wants to be polite (or impolite; cf. Culpeper 1996) because language users cooperate with each other in Grice's (1975) sense. For instance, by delivering bad news in an indirect way the speaker may violate various Gricean Cooperative Maxims (e.g., Quantity), but the speech partner will interpret this as an attempt to be (negatively) polite as language users collaborate to make sense to utterances. In the Brown and Levinsonian model, politeness (and impoliteness) are expressed vis-à-vis 'strategies', which are conventionalised forms of language use that one may deploy according to the needs of a particular interpersonal context.

The theory of Brown and Levinson (1987) has been unprecedentedly influential (see an overview in Szili 2007): it continues to be used after three decades, and in certain disciplines such as cognitive pragmatics it has remained an authoritative framework to theorise politeness. At the same 
time, soon after its publication it received heavy criticism, in particular from scholars such as Yueguo Gu (1990) and Sachiko Ide (1989) who worked on languages - most typically, Chinese and Japanese - that were less studied in pragmatics at that time (we will revisit this role of East Asian languages in critical sociopragmatic research in section 3). Such critiques argued that many of Brown and Levinson's analytic constructs reflect Western (predominantly Anglo) ontologies, and as such they may be dysfunctional or at least problematic if one deploys them in other cultural contexts - consequently, no universal model may ever capture politeness across languages and cultures in a uniform way. For instance, as Ide (1989) points out, the Brown and Levinsonian concept of 'strategy' is of limited use in examining how the Japanese express politeness. This is because it is grounded in the Western understanding that choosing the contextually 'most appropriate' interpersonal communicative behaviour will ultimately have a 'pay off'. According to Ide (1989), in honorific-rich languages such as Japanese, the use of language is by default not 'strategic': in the Japanese sociocultural context, linguistic norms rather than personal choices regulate the use of language forms (honorifics) by means of which politeness is expressed. In a similar fashion, $\mathrm{Gu}$ (1990) argued that the use of Chinese politeness in influenced by a set of norms, which simply cannot be described by the universalist inventory of Brown and Levinson. While the validity of such criticisms has been questioned to a certain degree (see e.g., Pizziconi 2011), they nevertheless demonstrate that to many the Brown and Levinsonian framework raises substantial problems.

Both the research that Brown and Levinson's (1987) framework has inspired, and its criticisms before the 2000s, are often referred to in the politeness field as first-wave politeness research (see both Xinren Chen and Dan Han, in the present issue). First wave research is bound together by a number of theoretical and methodological concepts (Kádár \& Haugh 2013), including the following:

1. Focus on the macro or cultural level of politeness, i.e., the question of how one can systematically describe politeness in a particular linguaculture or beyond;

2. Interest in dyadic interaction between a 'speaker' who produces an utterance and a 'hearer' who interprets the utterance (or writer and reader in the case of written texts);

3. Preference for studying the operation of politeness by using data that suits the analysis, such as hypothetic examples, elicited cases, and so on. 
Critiques of the first-wave of politeness research (e.g., Eelen 2001) argue that - due to the above characteristics - frameworks that have been inspired by the Brown and Levinsonian thought are a priori (or top-to-down) by nature as they use language data to prove assumptions. While in my view being a priori in itself is not a problem (indeed, one may rightly argue that being 'objective' and 'rigorous' is a myth in humanities), these critiques are important as they point to a question that many should rightly ask in areas of research where Brown and Levinson is still used, namely why would anyone reasonably use a theory like Brown and Levinson, which raises so many problems?

The first-wave of politeness research has received intensive academic criticism since the 2000s, when a completely new politeness paradigm appeared in the field. This paradigm is often referred to as the second-wave or discursive approach to (im)politeness research. Second wave approaches of representative value such as Eelen (2001), Watts (2003), and Mills (2003) argued that it is problematic to attempt to model the operation of politeness phenomena on the cultural level, i.e., to create macro models of politeness by means of which one can describe how politeness is used and interpreted beyond an actual interaction. The rationale behind this argument is that politeness comes into existence in the form of interpersonal evaluations (and often through a series of evaluative moments) in longer chunks of interaction, i.e., as a discursive construct, and no analytic theory can reliably predict how evaluation works in a particular moment. Since in the second-wave (im)politeness is understood to be a predominantly idiosyncratic or at least individual phenomenon, frameworks that represent a second-wave uptake argue that is difficult to the analyst to approach it through pragmatic 'models'. Accordingly, there is an underlaying assumption in second-wave politeness research, namely, that the goal of politeness research is to develop an analytic inventory to reliably analyse complex datasets (most typically, naturally occurring interactions), instead of delivering summative/systemising accounts of politeness in a particular lingua-culture. As part of the pursuit of capturing politeness as an interactional product, various researchers such as Watts (2003) and Locher (2006) raised through-provoking terminological (and related methodological) issues, which continue to receive significant attention in the politeness arena to the present-day (see, e.g., Kádár \& Zhang 2019; and Liu \& Shi, both in the present issue), such as how to disentangle popular (1st order, i.e., language user) and analytic (2nd order, i.e., academic) definitions of 'politeness'. Second wave research has pointed out that the Brown and Levinsonian and other first-wave approaches are problematic in that they 
rely exclusively on 1st order understandings of 'politeness', and also they 'code' what counts as politeness in a particular instance of language use themselves - by so doing, they unavoidably ignore language-user understandings and evaluations of language use.

Importantly, these 'waves' are not demarcated by a strict borderline: the notion of 'wave' is used in a rather practical way in the field, to distinguish major theoretical and methodological paradigms that have influenced the thinking of scholars working on politeness (van der Bom \& Grainger 2015). Thus, the boundaries of each of these 'waves' are lucid, and many so-called 'early' frameworks of politeness, which could easily be dismissed as first-wave and as such 'outdated', such as House (1989), include critical thought that makes such work relevant to research to date. The first-wave of politeness research did not cease to exist with the appearance of the second-wave (see, e.g., Terkourafi 2008). In addition, the second-wave has raised at least as powerful theoretical criticisms as the first-wave (see an overview in Kádár \& Haugh 2013). Such criticisms paved the way for a third-wave to emerge in the field since the 2010s. Essentially, in the ontology of the second-wave there is no such a thing as 'culture', due to the paradigmatic interest in how politeness varies across individual contexts. This view has left the field in a sense of limbo, in that in many other lines of pragmatic inquiry - spanning intercultural uptakes on language use (e.g., Spencer-Oatey 2000), through historical pragmatic inquiries into polite language use (e.g., Jucker 2010), to applied research on polite language use in workplaces (Holmes 2006) - culture is indispensable.

Studies that represent the third-wave of politeness research, such as Garces-Conejos Blitvich (2010), Culpeper (2011), Kádár \& Haugh (2013), Haugh (2015), and Kádár (2017) have returned to the Brown and Levinsonian pursuit of macro-modelling linguistic politeness across languages and cultures to a certain degree. However, unlike their first-wave counterparts, the body of third-wave approaches examines macro/lingua-cultural patterns of polite behaviour by merging qualitative and quantitative approaches, i.e., by interpreting politeness in terms of behavioural and evaluative tendencies. As a methodological change related to this focus on sociopragmatics tendencies, third-wave approaches have experimented with alternative approaches, such as the role of metapragmatic lexemes (Silverstein 1985) in understanding recurrences in evaluative behaviour (e.g., Kádár \& Haugh 2013).

The present special issue represents a predominantly third-wave line of thinking in the following respects: 
1. The contributions focus on pragmatic phenomena that are embedded in Chinese culture, such as the influence of the Chinese political culture on politeness behaviour (Dániel Kádár and Sen Zhang), the perhaps unprecedented diversity of Chinese first-person pronominal forms with complex sociopragmatic indexical meanings (Cher Leng Lee), the notion of 'unexpected' topic shift with specific salience in Chinese social interaction (Weihua Zhu), and so on and so forth. That is, while no contribution argues that the pragmatic phenomena studied may only exist in Chinese, they aim to capture politeness beyond the individual/idiosyncratic level of language use by making replicable analysis that helps us to understand a particular aspect of politeness use in Chinese lingua-culture.

2. The studies utilise larger datasets, and pursue interest in a number of phenomena, including face-to-face interaction (e.g., Chen; Kádár and Ning; Zhu), monologues (e.g., Fengguang Liu and Wenrui Shi; Kádár and Zhang), historical sources (Lee) and so on. Thus, the papers fit into the typical third-wave argument that politeness should be studied both in face-to-face freely co-constructed interaction and other datatypes, i.e., not datatype is off limit to the politeness researcher. While politeness often comes into existence in the form of evaluative moments - this is why the second-wave of politeness research is implicitly anchored in interaction studies - as per the third-wave thought studies in the present issue agree on that politeness can also be rigorously analysed in data where such evaluative moments cannot be observed.

3. As a related point, various papers experiment with research methodologies that count as alternatives to the purely interactional secondwave approach. While interactional evaluations are key in certain analyses (e.g., Zhu), some other papers (e.g., Liu \& Shi) explore politeness in settings in which interactional analysis would not work simply due to the nature of the data. Some others such as Ning and Kádár engage in multimodal research, e.g., by studying the relationship between linguistic and non-linguistic behaviour.

Following this synopsis of the development of the field and the theoretical position of the present special issue in linguistic politeness research, in what follows let us briefly discuss three areas where the contributions of this special issue particularly actively contribute to ongoing discussions in the field. 


\subsection{Three general areas of contribution}

In a variety of contributions to the special issue, morality and related language norms and ideologies play a key role. This focus on morality aligns with an important area of present day politeness theory, which arguably has relevance also to other 'applied' areas of linguistics such as sociolinguistics. To many who work in other (non-socially oriented) areas of linguistics, the concept of 'morality' may sound a somewhat alien or at least 'philosophical' term. However, recent years have witnessed a 'moral turn' in politeness research, in the respect that more and more researchers have pointed out that politeness behaviour and evaluations are anchored in normative moral routine perceptions of 'how things should be' (see, e.g., Culpeper 2011; Kádár \& Haugh 2013; Kádár 2017; Chang \& Fukushima 2017). Moral perceptions, norms and ideologies prevail in discourses on politeness, and also manifest themselves in the structure of interactions (Wuthnow 1989). The perceived breaches of morally authoritative norms and ideologies trigger (a) strong reactions, or 'gut feelings' (Haidt 2012), and (b) subsequent morally loaded metapragmatic reactions. The concept of morality opens up noteworthy theoretical vistas in politeness theories; perhaps most importantly, it provides a key for pragmaticians to (re-)incorporate a key aspect of 'culture' into politeness research (Spencer-Oatey \& Kádár 2016; Okano \& Brown 2018), since many moral norms and ideologies are culturally embedded, and cultural behavioural tendencies may be explained through the lens of morality and moral ideologies. In all contributions to this volume, such as Chen, Liu and Shi, Kádár and Ning, Zhu, and Kádár and Zhang, morality and moral ideologies play a central role. Due to space limitations, let us here refer to three papers as examples of how the special issue contributes to the moral turn in pragmatics. Liu and Shi examine national conflicts and related politeness behaviour, in which culturally situated moral values influence the rhetorical structure of arguments to such a degree that the arguments potentially lose their relevance in terms of politeness to those who come from other cultural backgrounds. Zhu argues that perceptions of how interactions should unfold - i.e., the moral order of things - are heavily influenced by Chinese cultural norms, by focusing on the phenomenon of unexpected topic switching as a case study. Unexpected topic switching in everyday communication would be face-threatening to native English speakers according to the existing literature. However, Zhu asserts that unexpected topic switching is appropriate to many native Chinese speakers in certain 
contexts. The interactants are not expected to switch topics after providing any cues, discourse markers or smooth transitions in informal settings in Mainland China, although they would be in formal settings. Therefore, context, including the sociocultural context, the interactional context, and the personal context, plays a role in the expected moral order of interactional events in the corpus of Zhu. Finally, Kádár and Zhang examine cases of monologues, in which engagement in moralising rather than strict-sense politeness behaviour operates as a form of 'alignment'. Thus, they explore instances of language use in which moralising discourse prevails over linguistic politeness, and due to this relationship politeness may only play a secondary albeit important and complex role in language use.

Another area of contribution that papers in this special issue deliver to politeness research is self-reflection: practically all of the contributions revisit many seemingly well-researched questions from a critical point of view. Due to space limitations, let us refer here to two articles. Cher Leng Lee examines Classical Chinese pronominal forms. Since Braun's (1988) authoritative monograph, many studies have investigated the question as to how pronominal forms relate to politeness (see a useful overview in $\mathrm{He}$ \& Ren 2016). This relationship has been a source of problems, due to the fact that on the one hand no linguistic form is inherently polite, while, on the other hand, pronominal forms tend to have strongly conventionalised pragmatic functions. Instead of engaging in discussing pronouns from this conventional point of view, Lee takes an innovative angle, as she examines the questions as to whether we can talk about pronouns as a homogenous sociopragmatic category in general and, if not, what this complexity implies for politeness theory. As her discussion reveals, in historical (Classical) Chinese there is a cluster of seemingly similar pronominal forms, which in language use index very different interpersonal meanings, and as such they fulfil significantly different sociopragmatic functions and are interrelated with linguistic politeness. In a similar fashion, Chen reviews the scope of ideology in politeness research. In a body of politeness literature - in particular in the second-wave of research (see Mills 2003 as a prime example) - ideology has been regarded as a problematic phenomenon, due to the fact that ideological views implicitly influence not only language use, but also analyst interpretations of politeness behaviour/evaluations. Chen's study intentionally incorporates ideology in its scope of analysis. That is, Chen self-reflexively questions the claim as to whether using ideology as a way of rationalising politeness behaviour is meant to be problematic, by deploying ideological constructs to examine Chinese data. 
In addition to these areas of contribution, the present special issue advances empirical research on pragmatics due to its Chinese focus. Studying seemingly 'exotic' data such as Chinese - although calling a language with over a billion speakers 'exotic' may be dubious to say the least - has a fundamental role in what scholars such as Hanks et al (2009) and Mey (2012) define as 'emancipatory pragmatics'. Following culturally based first-wave criticisms of Brown and Levinson (1987), such as the above-discussed works of Ide (1989) and $\mathrm{Gu}$ (1990), various scholars have pointed out that it is fundamental to use analytic theories and concepts that are grounded in lingua-cultures outside of the Western (predominantly Anglo) cultural sphere (e.g., Collins 1996; Anchimbe \& Janney 2011; Senft 2014: 189). In emancipatory research, East Asian languages have played a leading role (e.g., Mao 1994; Chen 2001), supposedly because the East Asian region has a very long intellectual history, in which proto-scientific research on language use - in particular, etiquette - has played a key role (Kádár 2007). Accordingly, East Asian languages are extremely rich in politeness-related metapragmatic concepts, which are significantly different from their English/Western counterparts (Haugh 2016). Research that capitalises on such concepts may not only help us to understand what is going on in East Asian data, but it also helps us to revisit conceptual issues in linguistic politeness research. Various contributions in the special issue represent an emancipatory line. For instance, Chen proposes 'family culture' as an analytic concept to understand the dynamics of Chinese politeness in a variety of settings. The emancipatory importance of this concept resides in that, as Chen points out, it may be problematic to theorise Chinese politeness behaviour by approaching interpersonal interaction as a phenomenon situated between individuals, since in Chinese society individual behaviour is interpreted in a familial nexus, and so the production and evaluation of politeness is often projected beyond the individual level. In a similar fashion, Lee's study is emancipatory by nature. By studying pronouns as conceptually very different from their Western counterparts, Lee's study implicitly raises the question as to whether we can accept theoretical frameworks that are based on Western understandings of linguistic categories such as pronominal forms. Still some other studies, such as Kádár and Ning point out that it is important to study forms of language use that have different social histories than their Western counterparts. By examining instances of public abuse and the role of language morality and impoliteness in these incidents, the paper of Kádár and Ning provides insight into the fact that in Chinese society there are public rituals used to 
the present day by means of which gendered ideologies rooted in Confucian philosophy are being reinforced. While one could simply dismiss these practices as unjust and socially inappropriate, and indeed the are perceived as inappropriate by many Chinese, they nevertheless need to be studied as they provide insight into the way in which language is used with a punitive function.

\section{Contents}

Since the previous section has overviewed the nature of the contribution the chapters make to the field, this concluding part only discusses briefly the rationale behind the orders of the contributions to the present special issue. The volume opens with the studies of Zhu, and Kádár and Ning, both of which focus on the moral domain of linguistic politeness, and as such contribute to the first area discussed in section 2.2. These studies are not only interconnected by their topical focus - even though Zhu studies a highly standard ('moral') domain of Chinese language use whereas Kádár and Ning venture into the realm of aggression ('immoral'). The next batch of papers including Liu and Shi, as well as Kádár and Zhang, has a predominantly self-reflexive focus, as it examines questions relating to basic understandings of 'politeness', such as whether certain deferential forms of language use can be interpreted as polite all. These papers use monologic data drawn from the Chinese political arena as their corpora. Finally, the papers of Chen and Lee represent an explicit emancipatory focus. The papers are followed by the thematic book review of Dan Han. The Postscript of Wei Ren reflects on the findings of the the volume.

\section{References}

Anchimbe, Eric and Richard W. Janney. Postcolonial pragmatics: An introduction. Journal of Pragmatics 43. 1451-1459.

Bom, Isabelle van der and Karen Grainger. 2015. Journal of Politeness Research: Introduction. Journal of Politeness Research 11. 165-178.

Braun, Friederike. 1988. Terms of address: Problems of patterns and usage in various languages and cultures. Berlin \& New York: Mouton de Gruyter.

Brown, Penelope and Stephen Levinson. 1987. Politeness: Some universals in language usage. Cambridge: Cambridge University Press.

Bull, Peter and Anita Fetzer. 2010. Face, facework and political discourse. Revue internationale de psychologie sociale 23. 155-183. 
Chang, Wei-Lin Melody and Saeko Fukushima. 2017. 'Your care and concern are my burden!': Accounting for emic concepts of 'attentiveness' and 'emphathy' in interpersonal relationships among Taiwanese females. East Asian Pragmatics 2. 1-23.

Chen, Rong. 2001. Self-politeness: A proposal. Journal of Pragmatics 33. 87-106.

Collins, Chik. 1996. The pragmatics of emancipation: A critical review of the work of Michael Huspek. Journal of Pragmatics 25. 791-817.

Culpeper, Jonathan. 1996. Towards an anatomy of impoliteness. Journal of Pragmatics 25. 349-367.

Culpeper, Jonathan. 2011. Impoliteness: Using language to cause offence. Cambridge: Cambridge University Press.

Culpeper, Jonathan, Michael Haugh and Daniel Z. Kádár 2017. Introduction. In J. Culpeper, M. Haugh and D. Z. Kádár (eds.) The Palgrave handbook of linguistic (im)politeness. Basingstoke: Palgrave Macmillan. 1-9.

Dynel, Marta. 2012. Swearing methodologically: The (im)politeness of expletives in anonymous commentaries on Youtube. Journal of English Studies 10. 25-50.

Eelen, Gino. 2001. A critique of politeness theories. Manchester: St Jerome.

Escandell-Vidal, Victoria. 2006. Towards a cognitive approach to politeness. Language Sciences 18. 629-650.

Garcés-Conejos Blitvich, Pilar. 2010. A genre approach to the study of im-politeness. International Review Of Pragmatics 2. 46-94.

García, Erica C. and Ricardo L. Ortheguy. 1983. Being polite in Ecuador: Strategy reversal under language contact. Lingua 61. 103-132.

Grice, Paul H. 1975. Logic and conversation. In P. Cole and J. Morgan (eds.) Syntax and semantics, Vol. 3. New York: Academic Press. 41-58.

Gu, Yueguo. 1990. Politeness phenomenon in modern Chinese. Journal of Pragmatics 14. $237-257$.

Haidt, Jonathan. 2012. The righteous mind: Why good people are divided by politics and religion. London: Penguin.

Hanks, William F., Sachiko Ide and Yasuhiro Katagiri. 2009. Towards an emancipatory pragmatics. Journal of Pragmatics 41. 1-9.

Haugh, Michael. 2015. Im/politeness implicatures. Berlin \& New York: Mouton de Gruyter.

Haugh, Michael. 2016. The role of English as a scientific metalanguage for research in. pragmatics: Reflections on the metapragmatics of 'politeness' in Japanese. East Asian Pragmatics 1. 39-71.

Haugh, Michael, Dániel Z. Kádár and Sara Mills. 2013. Interpersonal pragmatics: Issues and debates. Journal of Pragmatics.

http://dx.doi.org/10.1016/j.pragma.2013.09.009

He, Ziran and Wei Ren. 2016. Current address behaviour in China. East Asian Pragmatics 1. $163-180$.

Hock, Hans Henrich. 1991. Principles of historical linguistics. Berlin \& New York: Mouton de Gruyter.

Holmes, Janet. 2006. Workplace narratives. In A. De Fina, D. Schriffin and M. Bamberg (eds.) Discourse and identity. Cambridge: Cambridge University Press. 167-187.

Holmes, Janet and Maria Stubbe. 2015. Power and politeness in the workplace: A sociolinguistic analysis of talk at work. London: Routledge. 
Holtgraves, Thomas. 2005. Social psychology, cognitive psychology, and linguistic politeness. Journal of Politeness Research 1. 73-93.

House, Juliane. 1989. Politeness in English and German: The functions of please and bitte. In Sh. Blum-Kulka, J. House and G. Kasper (eds.) Cross-cultural pragmatics: Requests and apologies. Norwood, NJ: Ablex. 96-119.

Ide, Sachiko. 1989. Formal forms and 'discernment': Two neglected aspects of linguistic politeness. Multilingua 8. 223-248.

Jucker, Andreas H. 2010. 'In curteisie was set ful muchel hir lest'. Politeness in Middle English. In J. Culpeper \& D. Z. Kádár (eds.) Historical (im)politeness. Berne: Peter Lang. 175-200.

Kádár, Dániel Z. 2007. Terms of (im)politeness: On the communicational properties of historical Chinese terms of address. Budapest: Eötvös Loránd University.

Kádár, Dániel Z. 2017. Politeness, impoliteness and ritual: Maintaining the moral order in interpersonal interaction. Cambridge: Cambridge University Press.

Kádár, Dániel Z. and Michael Haugh. 2013. Understanding politeness. Cambridge: Cambridge University Press.

Kádár, Dániel Z. and Juliane House. 2019. Revisiting speech acts from the perspective of ritual: A discussion note. Multilingua. https://doi.org/10.1515/multi-2019-0002

Kim, Alan H. 2011. Politeness in Korea. In Mills \& Kádár (2011, 176-207).

Leech, Geoffrey. 1983. The principles of pragmatics. London: Longman.

Locher, Miriam. 2006. Polite behavior within relational work: The discursive approach to politeness. Multingua 25. 249-267.

Mao, LuMing. 1994. Beyond politeness theory: 'Face' revisited and renewed. Journal of Pragmatics 21. 451-486.

Mey, Jacob L. 2012. Societal pragmatics. Retrieved from: https://oi.org/10.1002/ 9781405198431.wbeal1081

Mills, Sara. 2003. Gender and politeness. Cambridge: Cambridge University Press.

Mills, Sara and Dániel Z. Kádár (eds.). 2011. Politeness in East Asia. Cambridge: Cambridge University Press.

Okano, Emi and Brown, Lucien. 2018. Did Becky really need to apologise? Intercultural evaluations of politeness. East Asian Pragmatics 3. 151-178.

Pizziconi, Barbara. 2011. Honorifics: The cultural specificity of a universal mechanism in Japanese. In Mills \& Kádár (2011, 45-70).

Senft, Günther. 2014. Understanding pragmatics. London: Routledge.

Silverstein, Michael. 1985. Language and the culture of gender: At the intersection of structure, usage, and ideology. In E. Mertz and R. Parmentier (eds.) Semiotic mediation: Sociocultural and psychological perspectives. Orlando: Academic Press. 219-259.

Spencer-Oatey, Helen. 2000. Introduction: Language, culture and rapport management. In Helen Spencer-Oatey (ed.) Culturally speaking. London \& New York: Continuum. $1-10$.

Spencer-Oatey, Helen and Dániel Z. Kádár. 2016. The bases of (im)politeness evaluations: Culture, the moral order and the East-West debate. East Asian Pragmatics 1. 73-106.

Szili, Katalin. 2007. Az udvariasság pragmatikája [The pragmatics of politeness]. Magyar Nyelvôr 131. 1-17. 
Terkourafi, Marina. 2008. Toward a unified theory of politeness, impoliteness, and rudeness.

In D. Bousfield and M. Locher (eds.) Impoliteness in language: Studies on its interplay with power in theory and practice. Berlin \& New York: Mouton de Gruyter. 45-74.

Watts, Richard. 2003. Politeness. Cambridge: Cambridge University Press.

Whutnow, Robert. 1989. Meaning and moral order: Explorations in cultural analysis. Berkeley: University of California Press.

Open Access. This is an open-access article distributed under the terms of the Creative Commons Attribution 4.0 International License (https://creativecommons.org/licenses/ by/4.0), which permits unrestricted use, distribution, and reproduction in any medium, provided the original author and source are credited, a link to the CC License is provided, and changes - if any - are indicated. (SID_1) 